\title{
Creep Deformation and Creep-rupture Behavior of Cr-Mo-V Steel Forgings
}

\author{
Yoshikuni KADOYA and Toru GOTO
}

Takasago Research \& Development Center, Mitsubishi Heavy Industries, Ltd., Shinhama, Arai-cho, Takasago, Hyogo-ken, 676 Japan.

(Received on December 28, 1989; accepted in the final form on May 18, 1990)

\begin{abstract}
In order to investigate creep deformation and the fracture mechanism of $\mathrm{Cr}-\mathrm{Mo}-\mathrm{V}$ steel, creep tests up to $10^{4} \mathrm{~h}$ were carried out in a temperature range of $550-675^{\circ} \mathrm{C}$. Metallographic observations were also conducted on the fractured specimens.

The results obtained are summarized as follows:

(1) Stress dependence of steady-state strain rate changes at a certain stress level, at all the temperatures studied. The stress levels of the transition in creep rate are close to those in fracture mode from transgranular to intergranular.

(2) The stress level at which instantaneous plastic deformation starts (regarded as the Orowan stress), is estimated to be $\sigma / E=1.5-2.0 \times 10^{-3}$. This Orowan stress corresponds with the transition stress described in (1).

(3) Above the Orowan stress, creep occurs mainly by the motion of dislocations within grains, which is controlled by the Orowan-boving mechanism. In this stress range, creep rupture ductility is high

(4) Below the Orowan stress, dislocations slowly climb over particles. Because of the slow deformation within grains, the contribution of intergranular sliding increases. This results in a greater chance of intergranular cavitation, and consequently, results in a low creep rupture ductility.
\end{abstract}

KEY WORDS: creep; ductility; fracture; $\mathrm{Cr}-\mathrm{Mo}-\mathrm{V}$ steel; Orowan stress; subgrain; cavitation.

\section{Introduction}

Gr-Mo-V steel is widely used for the critical components of fossil power plants; for example, steam turbine rotors, and its creep and fracture behavior have been investigated from various aspects. ${ }^{1-8)}$ In recent years, attention has been directed to the life assessment and extension of fossil power plants. The authors have examined life estimation based on the non-destructive observations of creep damage on this material and have proposed some feasible techniques..$^{9,10)}$

It is considered that the high creep strength of Gr-Mo-V steel is attributable mainly to uniformly dispersed carbides. Microstructural studies ${ }^{1-8)}$ on this material have shown that at elevated temperatures the precipitates coarsen and creep cavitation and a change in dislocation substructure take place. These microstructural changes also occur simultaneously during high temperature use. However, no systematic study has been reported on the relation between the microstructural changes and creep behavior. To improve the reliability of the life estimation based on a non-destructive evaluation of creep damage, it is necessary to clarify this relationship.

This study aims at studying creep deformation and fracture mechanism of $\mathrm{Cr}-\mathrm{Mo}-\mathrm{V}$ steel in conjunction with its microstructural changes. Using $1 \mathrm{Cr}-1 \mathrm{Mo}-$ $1 / 4 \mathrm{~V}$ steel cut from a retired rotor, we carried out long-term creep tests. Based on microstructural observation, the relation between the microstructures and creep deformation and creep-rupture behavior is discussed.

\section{Materials and Experimental Procedure}

\subsection{Materials}

The material used was a $\mathrm{Cr}-\mathrm{Mo}-\mathrm{V}$ steel turbine rotor retired after $100000 \mathrm{~h}$ of service. The specimens were cut from the center bore of the cold-end region in the circumferential direction. Table 1 shows the chemical composition and the heat treatment of the Cr-Mo-V steel studied. The specimens had a tempered bainite structure and the grain size of preaustenite was about $100 \mu \mathrm{m}$ (ASTM No. 3-4).

\subsection{Creep Tests}

The specimens were smooth bars of $8 \mathrm{~mm}$ in diameter, with $40 \mathrm{~mm}$ in gauge length. Creep tests were conducted by simple lever-arm creep machines. The testing conditions were selected in a temperatures range from 500 to $675^{\circ} \mathrm{C}$ at $25^{\circ} \mathrm{C}$ intervals, with stress

Table 1. Chemical composition and heat treatment of Cr-Mo-V steel studied. (wt\%)

\begin{tabular}{|c|c|c|c|c|c|c|c|c|c|c|c|c|c|}
\hline C. & $\mathrm{Si}$ & $\mathrm{Mn}$ & $\mathrm{S}$ & $\mathrm{P}$ & $\mathrm{Ni}$ & $\mathrm{Cr}$ & Mo & $\mathrm{V}$ & $\mathrm{Cu}$ & $\mathrm{Al}$ & $\mathrm{Sn}$ & As & $\mathrm{Sb}$ \\
\hline 0.30 & 0.25 & 0.75 & 0.008 & 0.008 & 0.35 & 1.23 & 1.20 & 0.26 & 0.15 & 0.005 & 0.017 & 0.016 & 0.003 \\
\hline
\end{tabular}

Heat treatment : $970^{\circ} \mathrm{C} \times 22 \mathrm{~h} \rightarrow \mathrm{Fan}$ cool $\rightarrow 665^{\circ} \mathrm{C} \times 67 \mathrm{~h} \rightarrow$ Furnace cool 
levels from 7 to $40 \mathrm{~kg} / \mathrm{mm}^{2}$. Test duration was from $10^{2}$ up to $1.5 \times 10^{4} \mathrm{~h}$.

\subsection{Metallographic Observations}

The specimens deformed up to rupture were subjected to microstructural studies. Optical microscopic observations were conducted on the longitudinal sections to investigate the creep fracture mode. To examine microstructural change during creep, extraction replica specimens (for carbide morphology) and thin-foil specimens (for dislocation structures) were cut from portions more than $10 \mathrm{~mm}$ apart from the rupture surface. The shape, distribution and average interspacing of carbides within grains were measured by an image analyzer. Nithal ( $5 \%$ ethyl nitrate alcohol solution) was used for the extraction. The thin-foil specimens were electrolytically polished using the twin-jet method in a $10 \%$ perchloric acid ethyl alcohol solution.

\section{Experimental Results}

\subsection{Creep Behavior}

Representative creep curves at $550^{\circ} \mathrm{C}$ are shown in Fig. 1. In order to compare creep curves at different stress levels, the abscissa is normalized by rupture time $t_{r}$. All creep curves show the typical one consisting of primary, secondary and tertiary creep regions. Creep acceleration in the tertiary creep region delays and the strain to rupture lowers as stress is reduced. These trends were common to all the temperatures tested in this work.

Rupture time is plotted in Fig. 2 as a function of applied stress. Based on the results to be mentioned in Sec. 3.2, the symbols are classified into 2 groups; the open symbols, that is, the transgranular fracture, and the solid symbols, that is, the intergranular fracture with creep cavitation. (These symbols have the same meanings in the other figures.) The boundary of the transition from the transgranular fracture to the intergranular fracture shows an acute curve. This fracture mechanism map corresponds well with that proposed by Shin-ya et al., ${ }^{11)}$ except a slight difference in the position of the boundary. The iso-thermal creep rupture curves are divided into 2 straight lines. The reason for this will be mentioned later. The bent points appear to be close to the boundary of the fracture mechanisms.

Fig. 3 shows the relation of fracture elongation and reduction of area to the rupture time. Both the fracture elongation and the reduction of area decrease as the rupture time becomes longer. In the short rupture time range, specimen fracture transgranularly and the ductility parameters tend to be higher at higher temperatures. In the long rupture time range, intergranular fracture takes place and there is no systematic change in the ductility parameters with temperature.

Fig. 4 shows the steady-state strain rate* $v s$. the applied stress diagram. From this figure one can obtain

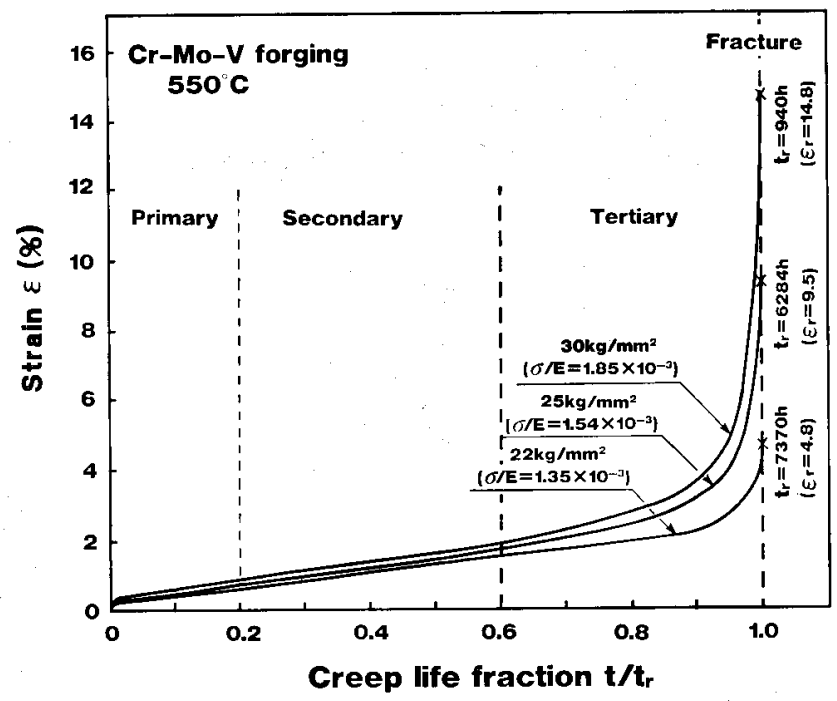

Fig. 1. Creep curves of $\mathrm{Cr}-\mathrm{Mo}-\mathrm{V}$ steel at $550^{\circ} \mathrm{C}$.

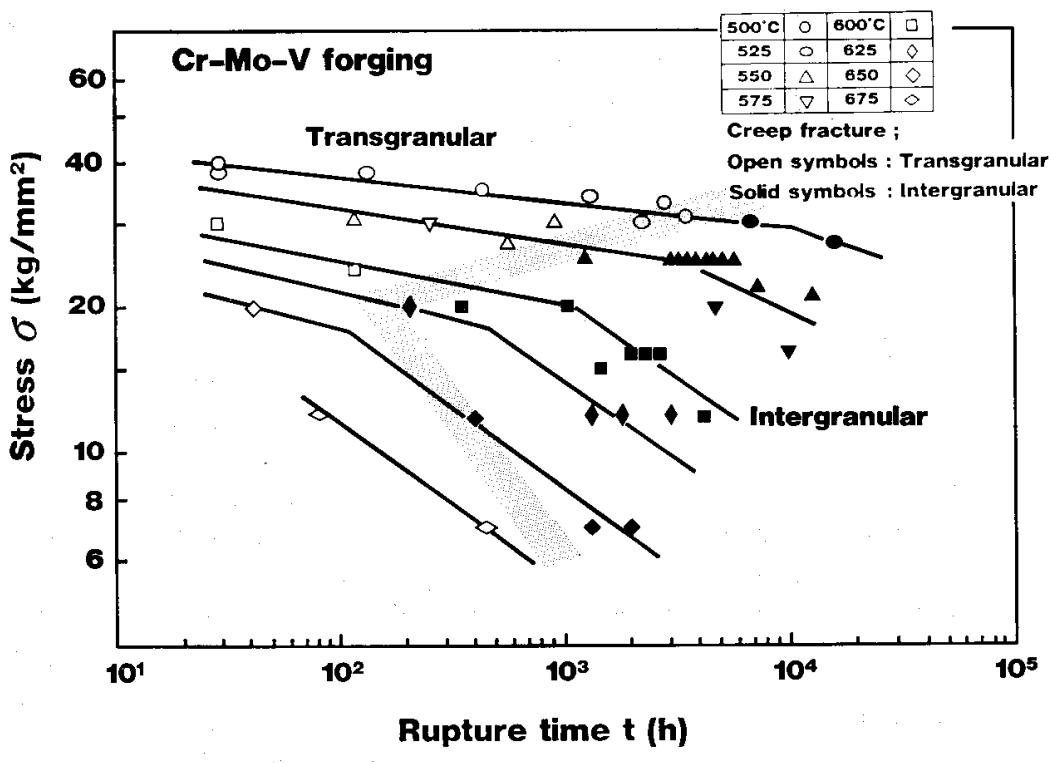

Fig. 2.

Applied stress $v s$. rupture time curves of $\mathrm{Cr}-\mathrm{Mo}-\mathrm{V}$ steel.

\footnotetext{
* The minimum strain rate $\dot{\varepsilon}_{m}$ was taken as steady-state strain rate $\dot{\varepsilon}_{s}$.
} 
stress exponents. A transition in stress exponent from 14 to 4 took place at the stress levels of $20-24 \mathrm{~kg} / \mathrm{mm}^{2}$ and this transition takes place near the boundary be-

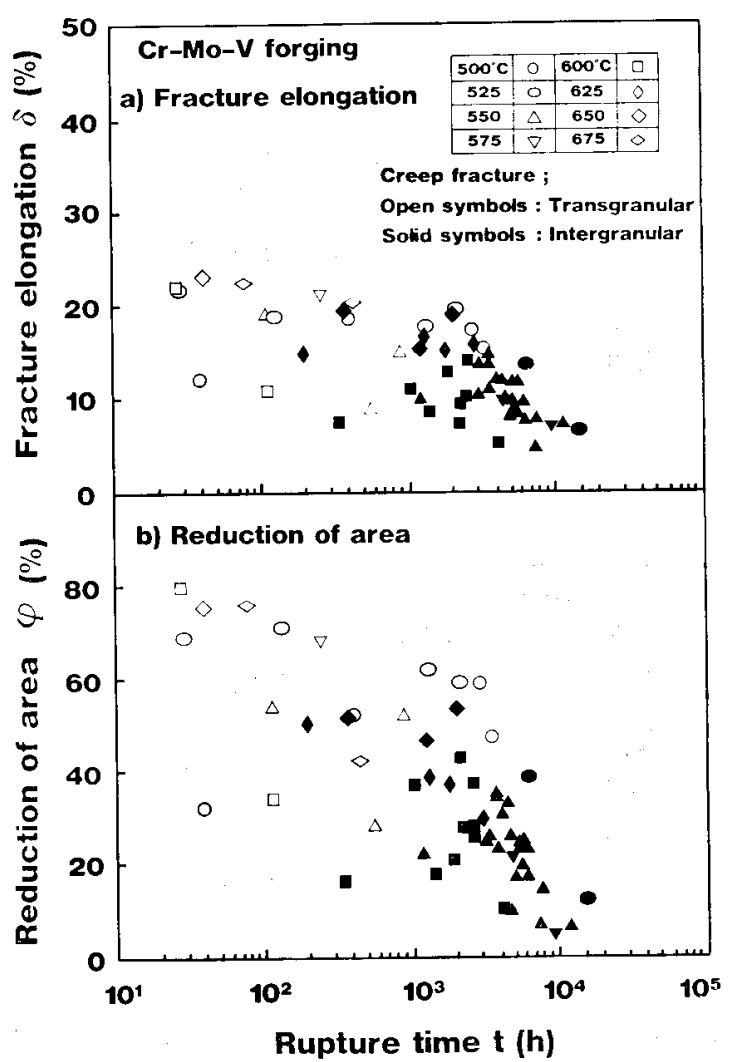

Fig. 3. Time dependence of fracture elongation and reduction of area of $\mathrm{Cr}-\mathrm{Mo}-\mathrm{V}$ steel.

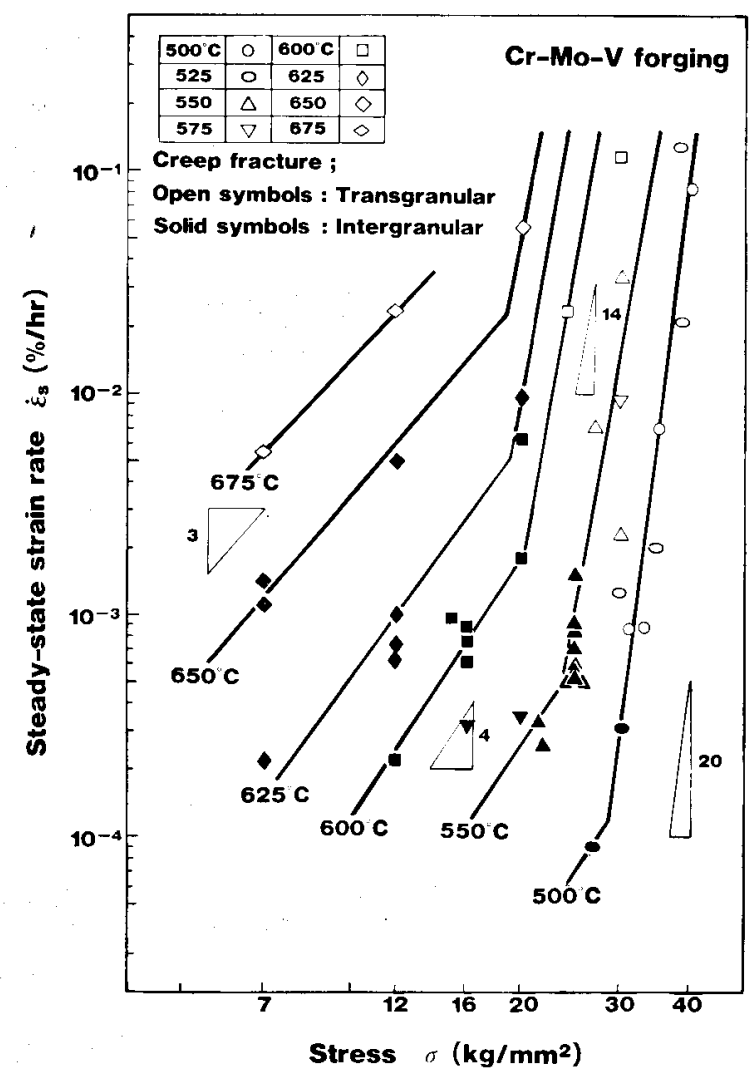

Fig. 4. Steady-state strain rate $v s$. applied stress diagram of Cr-Mo-V steel. tween the two fracture modes. This suggests that the creep-deformation mechanism changes through the transition region. ${ }^{8)}$ The same is true at other temperatures although the transition stress increases when the temperature is lowered. As is clear in Figs. 2 and 4, intergranular fracture takes place in the low stress region where time to rupture and $\dot{\boldsymbol{s}}_{s}$ show a low stress exponent. At $675^{\circ} \mathrm{C}$, however, transgranular rupture occurs in this stress region. This temperature $\left(675^{\circ} \mathrm{C}\right)$ is the same as the tempering temperature of this steel. This may be a reason for the different fracture mode.

It is known that the following Monkman-Grant relation holds between time to rupture $t_{r}$ and steadystate strain rate $\dot{\varepsilon}_{s}$ in a variety of materials. ${ }^{2 \text { ) }}$

$$
t_{r} \cdot \dot{\varepsilon}_{s}=C \quad C: \text { Constant }
$$

A similar relation was found in this work as shown in Fig. 5, i.e.,

$$
\log t_{r}=0.603-0.892 \log \dot{\varepsilon}_{s} .
$$

$t_{r}$ is also closely related to time to the onset of tertiary creep $t_{t}$ as shown in Fig. 6:

$$
\log t_{r}=0.222+\log t_{t} .
$$

The relations of Eqs. (2) and (3) hold regardless of the fracture mode.

\subsection{Fracture Mode Observations}

Fig. 7 shows representative optical microstructures near fracture surfaces. The two specimens were tested at the same stress level $\left(20 \mathrm{~kg} / \mathrm{mm}^{2}\right)$ at different temperatures $\left(600\right.$ and $650^{\circ} \mathrm{C}$ ). The fracture mode was classified into (a) transgranular creep fracture and (b) intergranular creep fracture with intergranular cavitation. The fracture modes of the other specimens

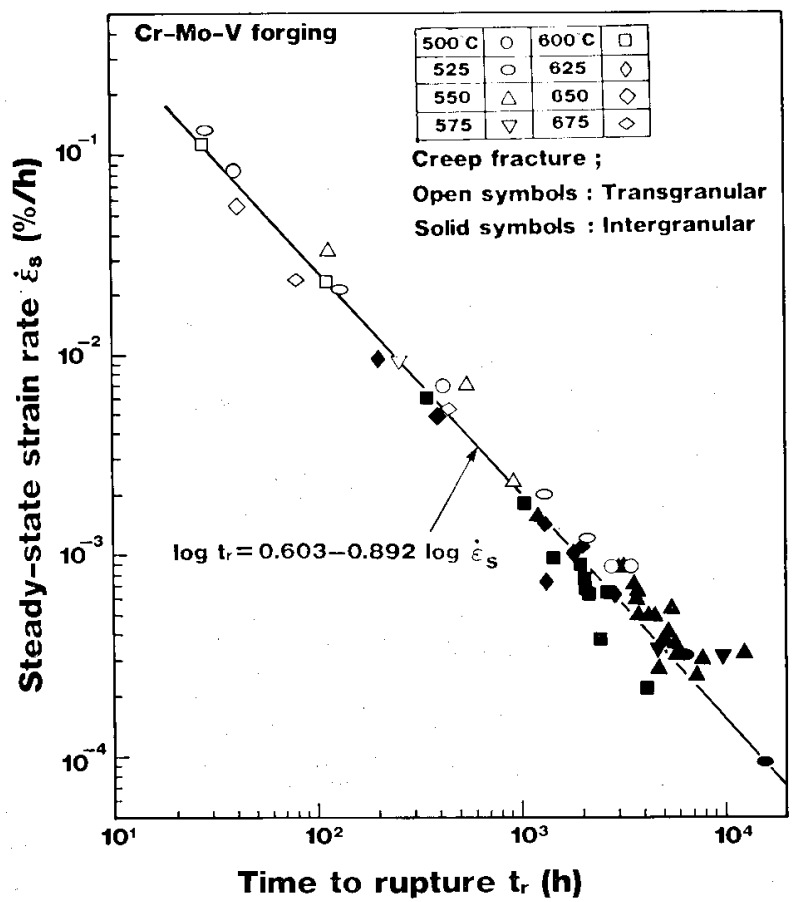

Fig. 5. Relationship between time to rupture and steadystate strain rate of $\mathrm{Gr}-\mathrm{Mo}-\mathrm{V}$ steel. 


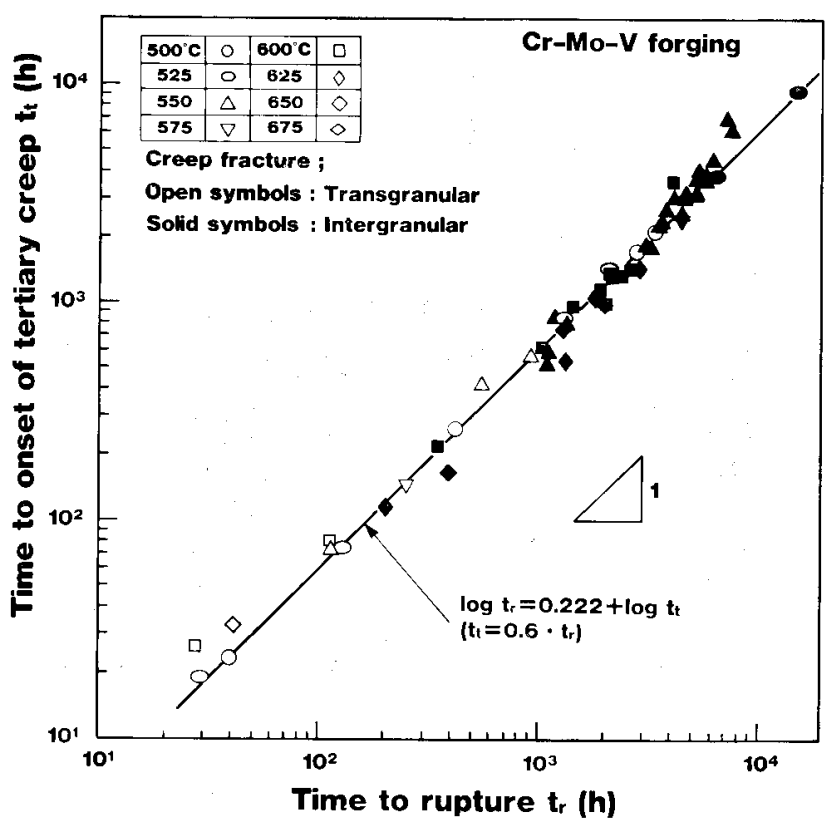

Fig. 6. Relationship between time to rupture and time to the onset of tertiary creep of $\mathrm{Cr}-\mathrm{Mo}-\mathrm{V}$ steel.
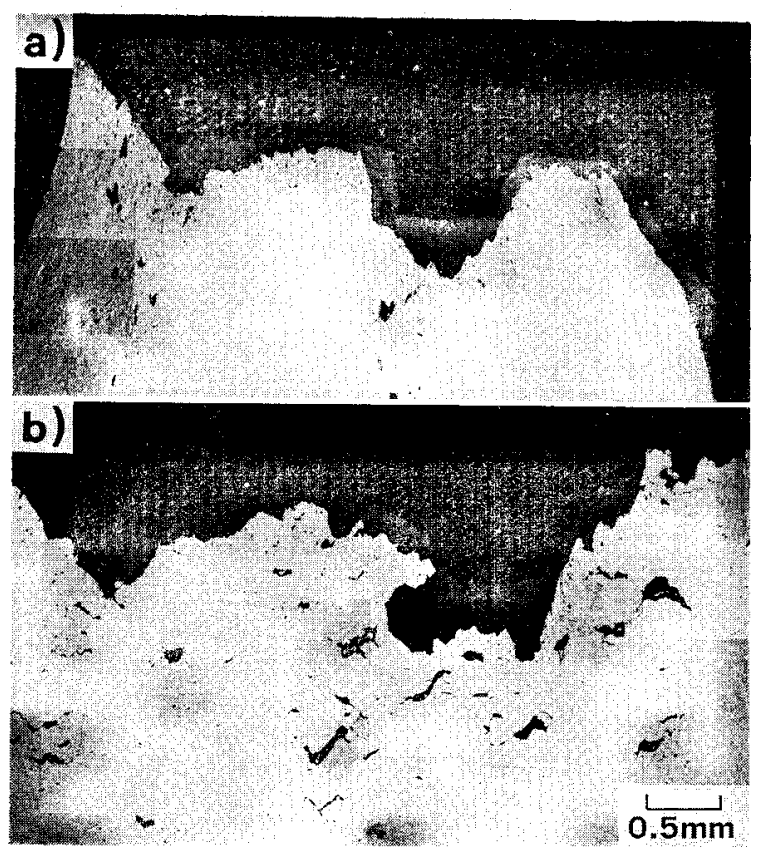

(a) tou C. $20 \mathrm{~kg} \mathrm{~mm}^{2}$, , , $=42 \mathrm{~h}$ (transgranular creep fracture)

(b) $600^{\circ} \mathrm{C}-20 \mathrm{~kg} / \mathrm{mm}^{2}, t_{r}=1060 \mathrm{~h}$ (intergranular creep fracture)

Fig. 7. Optical microstructures near rupture surface.

belong to either (a) or (b).

\subsection{Carbide Morphology Observations}

Fig. 8 shows an extraction replica of the crept specimens. The samples were cut from the portion where the specimens were still in uniform elongation. The ordinate is the test temperature and the abscissa is the test stress. The location of the micrographs indicates their test conditions. The white and dark parts represent, respectively, the transgranular creepfracture and the intergranular creep-fracture region.
The figures attached to each photograph represent the average carbides interspacing within grains $\lambda$ $(\mu \mathrm{m})$.

The intergranular precipitates are mostly $\mathrm{M}_{23} \mathrm{C}_{\mathfrak{6}}$ or $\mathrm{Fe}_{3} \mathrm{C}$. Precipitates within grains were identified as $\mathrm{V}_{4} \mathrm{C}_{3}, \mathrm{Mo}_{2} \mathrm{C}$ (needle) and $\mathrm{Fe}_{3} \mathrm{C}$. At temperatures ranging from 500 to $675^{\circ} \mathrm{C}$, there was no change in the types of precipitates.

At temperatures ranging from 500 to $550^{\circ} \mathrm{C}$, both the transgranular and intergranular carbides displayed no noticeable coarsening, while substantial coarsening was found at temperatures ranging from 600 to $650^{\circ} \mathrm{C}$. Especially at 12 or $7 \mathrm{~kg} / \mathrm{mm}^{2}$ and at $650^{\circ} \mathrm{C}$, intergranular carbides coarsened to blocky shapes and the average interspacing of transgranular carbides after creep under these conditions was 1.5 times larger than those of other specimens. The aspect ratio of spheroidized transgranular carbides was almost the same under all test conditions (about 1.7).

\subsection{Dislocation Substructure Observations}

Fig. 9 shows the transmission electron micrographs of the crept specimens in the uniformly deformed portions. The intergranular and transgranular fracture regions are marked by the dark and white areas, respectively. In the transgranular fracture region, the dislocation density is high and dislocations are nonuniformly distributed: clusterings of dislocations are seen in the region. In the intergranular fracture region, the dislocation density is low and dislocations are uniformly distributed. Some photographs in this region show the formation of subgrain structures; particularly, at $650^{\circ} \mathrm{C}$ and $7 \mathrm{~kg} / \mathrm{mm}^{2}$, subboundaries are formed, linking carbide particles dispersed within grains.

The substructural observations mentioned above suggest that dislocations move in the different manners between high and low stress regions. At higher stresses, dislocations pass freely through precipitates and interact mainly with other dislocations, forming clusters of dislocations. At low stresses, on the other hand, most dislocations are pinned by or piled up against the particles and are slowly climb-by-passing the particles. This results in a well recovered dislocation substructure, i.e., subboundary formation.

\section{Discussion}

\subsection{Creep Deformation Behavior}

The creep behavior mentioned in the preceding section suggests that creep of $\mathrm{Cr}-\mathrm{Mo}-\mathrm{V}$ steel is similar to that of a dispersion-strengthened alloy, ${ }^{13,14)}$ In regard to the creep of a precipitation-strengthened alloy, ${ }^{15}$ it has been proposed that the rate controlling process of creep deformation changes at the Orowan stress level. Below the Orowan stress, recovery (climbing of dislocations) controls creep, while above it dislocations pass through precipitates by the Orowanbowing mechanism. A recent study by Maruyama and Oikawa ${ }^{16)}$ suggests that the mechanism change occurs in practical heat-resisting alloys having com- 


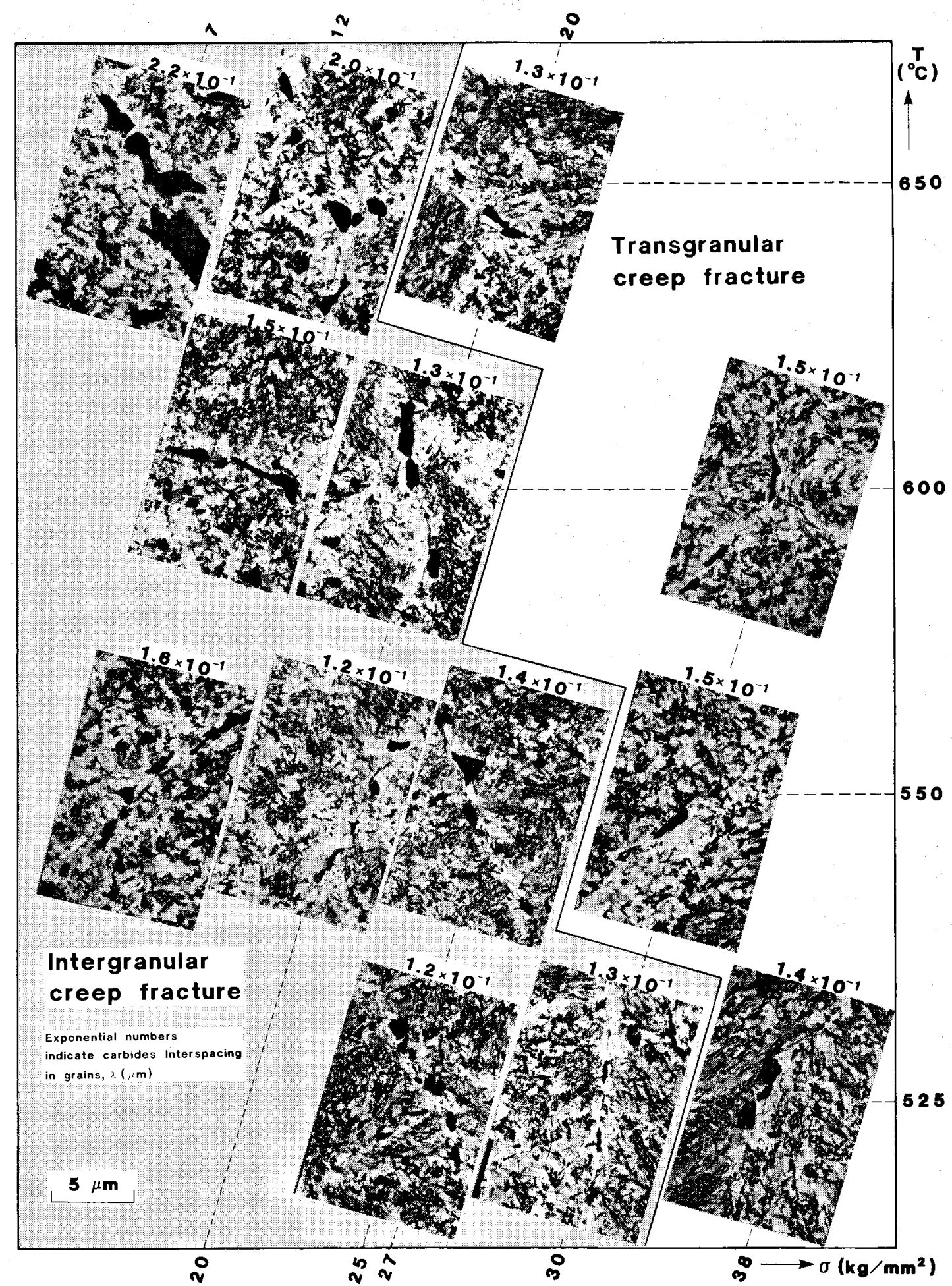

Fig. 8. Extraction replica of crept specimen.

(The location of the photographs represents temperature/stress conditions.)

plex microstructures. They measured the Orowan stress level at creep temperature from the stress dependence of instantaneous strain upon loading.

Fig. 10 shows the stress-strain curve of $\mathrm{Cr}-\mathrm{Mo}-\mathrm{V}$ steel at creep temperatures; in (a) strain, $\varepsilon$ at the end of the first quarter cycle of low-cycle fatigue tests is plotted against normalized stress $\sigma / E$. In (b) initial strain, $\varepsilon_{i}$ at the start of creep test is plotted against normalized stress $\sigma / E$. In (b), the $\varepsilon-\sigma / E$ curve of (a) is indicated for a reference to estimate the stress at which instantaneous plastic deformation starts. The $\varepsilon_{i}$ values measured at various temperatures fall along the $\varepsilon-\sigma / E$ curve. From this figure, the stress level at which instantaneous plastic deformation starts (regarded as the Orowan stress) is estimated to be $\sigma / E$ $=1.5-2.0 \times 10^{-3}$.

The Orowan shear stress $\tau_{o r}$ is related to the average carbides interspacing in grains $\lambda$ by $^{17)}$

$$
\tau_{o r}=G b / \lambda
$$




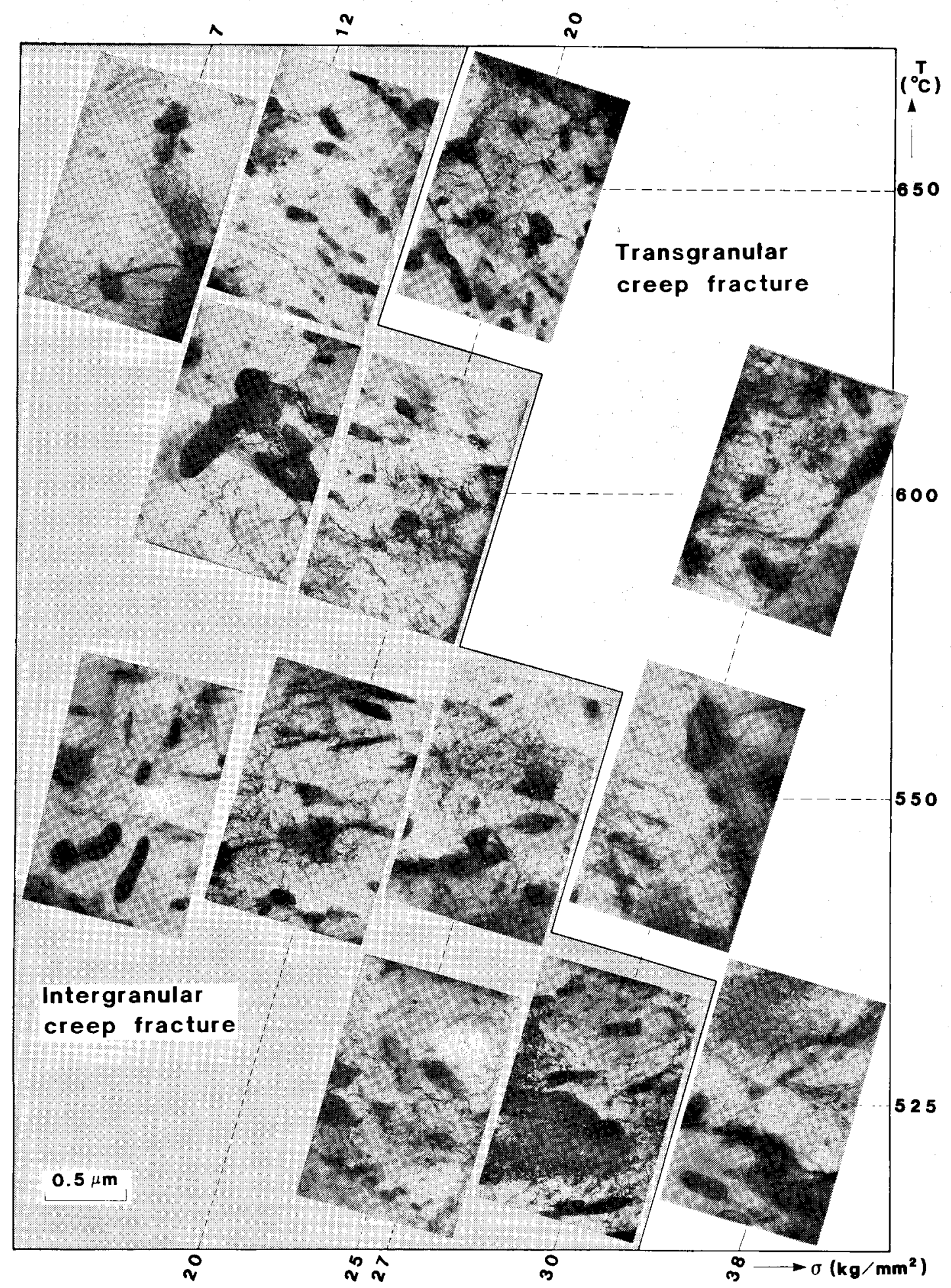

Fig. 9. Transmission electron micrograph of crept specimen.

(The location of the photographs indicates temperature/stress condition.)

where, $b$ : Burgers vector

$G$ : the shear modulus.

The average value of $\lambda$ at 525 and $550^{\circ} \mathrm{C}$ in Fig. 8 is $1.4 \times 10^{-7} \mathrm{~m}$. The following equation holds between $G$ and Young's modulus $E$ :

$$
G=E / 2(1+\nu),
$$

where, $\nu$ : the Poisson ratio.

Shear stress $\tau$ and tensile stress $\sigma$ are related to each other by

$$
\tau=\sigma / M
$$

where, $M:$ the Taylor factor.

The Taylor factor varies with the slip system. When only $\{110\}\langle 111\rangle$ is available, $M$ is equal to 3.067 . For pencil gride around $\langle 111\rangle$ zone axis, $M$ is reduced to $2.733 .{ }^{18)}$ In actual materials, $M$ should take a value between the two. From Eqs. (4) through (6), $\sigma_{O r} / E$ is expressed as

$$
\sigma_{o_{r}} / E=M b / 2(1+\nu) \lambda .
$$



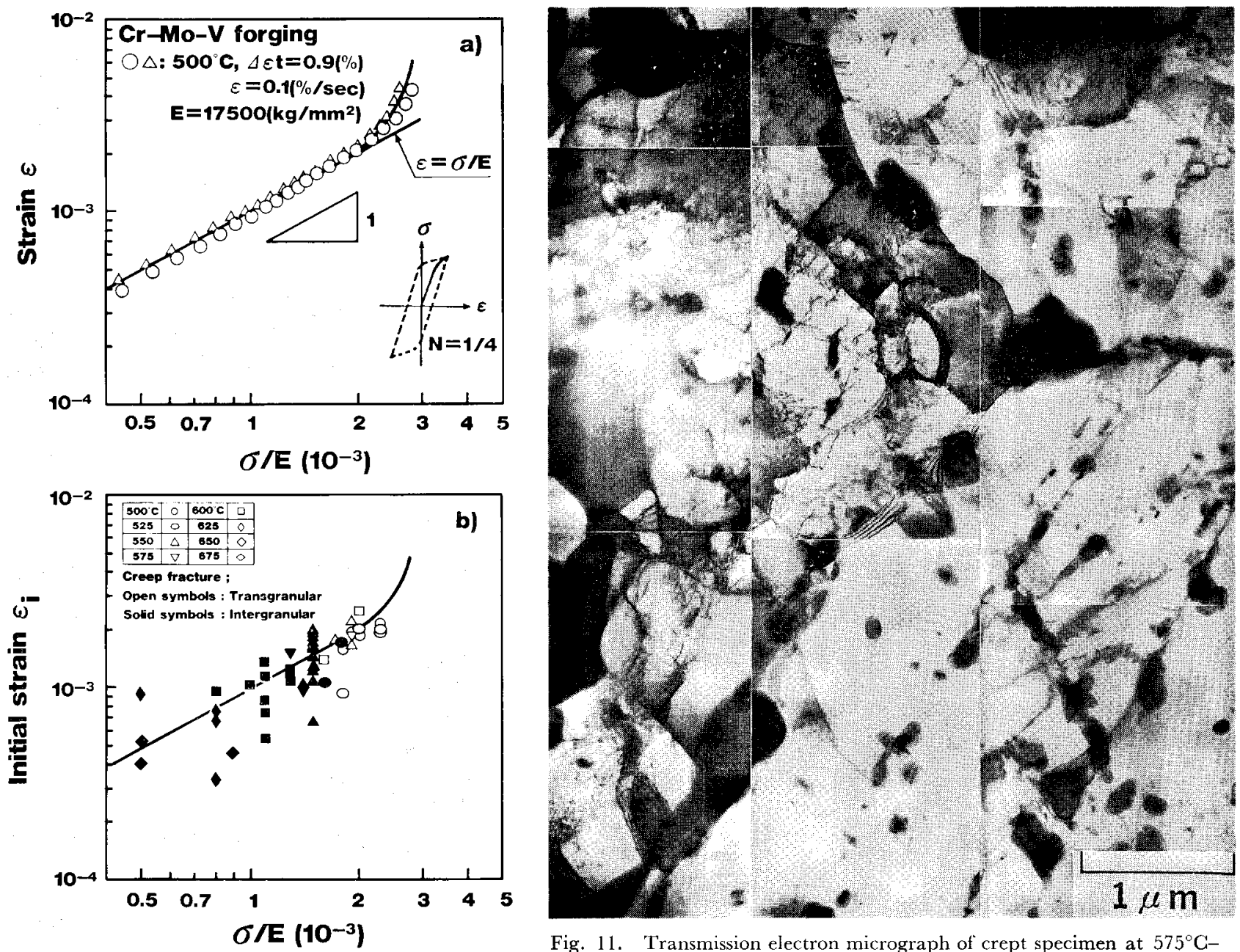

Fig. 11. Transmission electron micrograph of crept specimen at $575^{\circ} \mathrm{C}-$ $16 \mathrm{~kg} / \mathrm{mm}^{2}, t_{r}=9694 \mathrm{~h},\left(\sigma / E=1.0 \times 10^{-3}\right)$.

creep temperatures, (a) measured by low cycle fatigue test and (b) obtained from initial strain at the start of creep test.

Taking $b=2.5 \times 10^{-10} \mathrm{~m}, \nu=0.3, \lambda=1.4 \times 10^{-7} \mathrm{~m}$ and $M=2.733-3.067, \sigma_{O r} / E=1.9-2.1 \times 10^{-3}$. This value corresponds well with the yield stress at which instantaneous plastic deformation was detected in Fig. 10. This result points out that Orowan stress arises from the presence of transgranular carbides.

The stress range of this work is from 0.5 to $2.5 \times$ $10^{-3} \mathrm{E}$. These stresses are included in the diffusioncreep region controlled by the intergranular diffusion in which the stress exponent $n$ is 1 , according to the deformation mechanism map ${ }^{19}$ of $1.0 \mathrm{Cr}-0.6 \mathrm{Mo}-0.3 \mathrm{~V}$ steel drawn by Ashby. Fig. 4, however, indicates that the measured values of $n$ are about 3 or more, suggesting that deformation is caused by dislocation creep. Fig. 11 is a transmission electron micrograph at a stress below the Orowan stress level $(\sigma / E=1.0 \times$ $\left.10^{-3}\right)$. The high dislocation density observed before the tests was reduced to a low dislocation density and well-developed subgrains are formed. This observation indicates that recovery of dislocation and, therefore dislocation creep, took place during creep. The stress condition for actual components $(\sigma / E=0.5$ $\left.1.5 \times 10^{-3}\right)$ is located below the Orowan stress level. It appears that creep deformation controlled by the

recovery of dislocations will occur under the actual service conditions.

\subsection{Relation between Creep Deformation and Creep-rup- ture Behavior}

As mentioned above, the creep deformation mechanism of $\mathrm{Cr}-\mathrm{Mo}-\mathrm{V}$ steel seems to change at the Orowan stress. This difference in creep mode will influence the creep fracture. In fact, the fracture mode of $\mathrm{Cr}-\mathrm{Mo}-\mathrm{V}$ steel corresponded well to the change in creep deformation behavior. That is, the creep fracture mode changed from a transgranular fracture at high stresses to an intergranular fracture at low stresses at the boundary near the Orowan stress level. At the boundary, the applied stress $v s$. the rupture time curves also changed their slope.

Fig. 12 shows the relation between strain to the onset of tertiary creep $\varepsilon_{\imath}$ and $\sigma / E$. In the range of $\sigma / E=0.5-1.5 \times 10^{-3}$, i.e., in the intergranular fracture region, the average value of $\varepsilon_{t}$ is $1.0 \times 10^{-2}$. Above $\sigma / E=1.5 \times 10^{-3}$, namely in the transgranular fracture region, the average value of $\varepsilon_{t}$ takes a higher value of $2.5 \times 10^{-2}$. In the case of transgranular fracture, the strain to the onset of tertiary creep is 2.5 times larger than that in the case of intergranular fracture. This change in ductility occurs near the Orowan stress level and should come from a change in creep deformation 


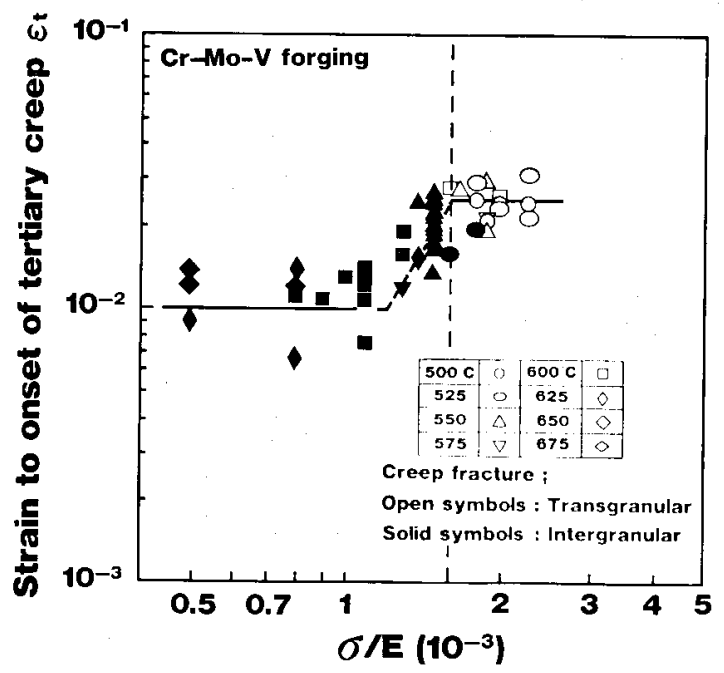

Fig. 12. Relation between strain to the onset of tertiary creep and $\sigma / E$.

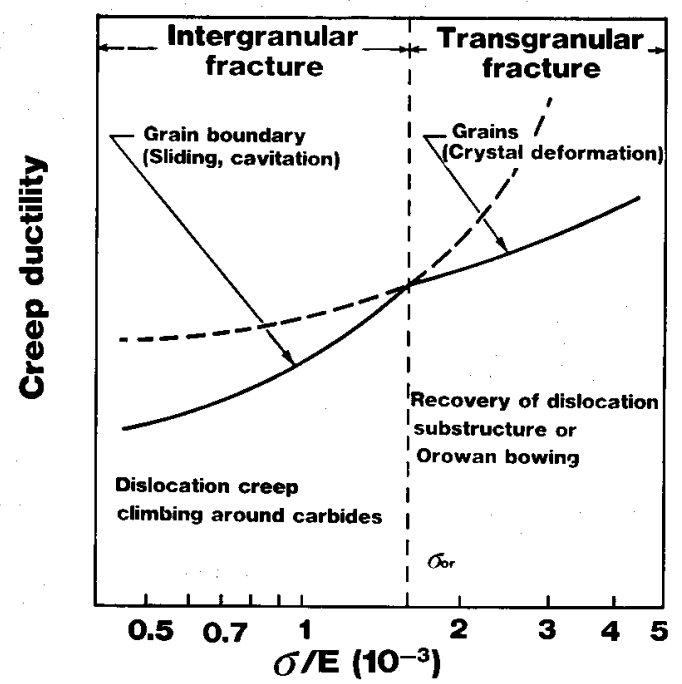

Fig. 13. Schematic representations of creep mechanism.

mode.

The results mentioned above are summarized as Fig. 13. At stresses higher than $\sigma_{o r}$, dislocations pass through precipitates by the Orowan-bowing and creep occurs mainly by deformation within grains. This results in higher creep ductility. In contrast, at stresses lower than $\sigma_{0}$, the dislocations move slowly due to the pinning by the particles. Because of the slow deformation within grains, the contribution of intergranular sliding increases. This results in a greater chance of intergranular cavitation and consequently, low creep ductility.

\section{Conclusions}

In order to clarify creep deformation and the fracture mechanism of $\mathrm{Cr}-\mathrm{Mo}-\mathrm{V}$ steel, we carried out creep tests up to $10^{4} \mathrm{~h}$ at temperatures ranging from $500-675^{\circ} \mathrm{C}$. Metallographic observations were conducted on the fractured specimens. The results are summarized as follows.

(1) At temperatures ranging from 500 to $675^{\circ} \mathrm{C}$, all creep curves show the typical one consisting of primary, secondary and tertiary creep regions. Creep acceleration in the tertiary creep region delays and the strain to rupture lowers as stress is reduced.

(2) In the transgranular fracture region, the dislocation density is high and dislocations are nonuniformly distributed: clusterings of dislocations are seen in the region. In the intergranular fracture region, the dislocation density is low and dislocations are uniformly distributed. Some photographs in this region show the formation of subgrain structures; subboundaries link carbide particles dispersed within grains.

(3) Stress dependence of steady-state strain rate changes at a certain stress level, at all the temperatures studied. The transition stresses of stress exponent are close to those of fracture mode from transgranular to intergranular.

(4) The stress level at which instantaneous plastic deformation starts (regarded as the Orowan stress), is estimated to be $\sigma / E=1.5-2.0 \times 10^{-3}$. This Orowan stress level corresponds with the transition stress described in (3).

(5) Above the Orowan stress level, creep occurs mainly by the motion of dislocation within grains; dislocations pass freely through precipitates and interact mainly with other dislocations, forming clusters of dislocations. In this stress range creep rupture ductility is high.

(6) Below the Orowan stress level, dislocations have to climb over particles; eventually, subgrain formation occurs. Because of the slow deformation within grains, the contribution of intergranular sliding increases. This results in a greater chance of intergranular cavitation, and consequently, results in a low creep rupture ductility.

(7) The scrvice conditions of actual components is located below the Orowan stress level.

\section{Acknowledgment}

The authors wish to thank Dr. K. Maruyama of Tohoku University for his helpful advice.

\section{REFERENCES}

1) K. R. Williams: Mater, Sci. Eng., 28 (1977), 289.

2) H. R. Tipler and B. E. Hopkins: Met. Sci., 10 (1976), 47.

3) N. Shin-ya and S. R. Keown: Met. Sci., 13 (1979), 89.

4) T. Matsuo, T. Kisanuki, R. Tanaka and S. Komatsu: Tetsu-to-Hagané, 70 (1984), 565.

5) K. Kimura, T. Kisanuki, S. Komatsu, T. Matsuo and R. Tanaka: Tetsu-to-Hagané, 71 (1985), 1803.

6) K. Kimura, T. Matsuo, M. Kikuchi and R. Tanaka: Tetsu-to-Hagané, 72 (1986), 474.

7) K. Kimura, N. Ohi, T. Matsuo, M. Kikuchi and R. Tanaka: Tetsu-to-Hagané, 74 (1988), 1641.

8) D. A. Miller, W. T. Plumbridge and R. A. Bartlet: Met. Sci., 15 (1981), 413.

9) T. Goto: J. Soc. Mater. Sci., Jpn., 32 (1983), 563.

10) Y. Kadoya and T. Goto: J. Soc. Mater. Sci., Jpn., 36 (1987), 999.

11) N. Shin-ya, S. Yokoi and J. Kyono: Tetsu-to-Hagané, 70 (1984), A237.

12) F. C. Monkman and N. J. Grant: Proc. ASTM, 56 (1956), 593. 
13) P. L. Threadgill and B. Wilshire: Met. Sci., 8 (1974), 117.

14) J. J. Stephens and W. D. Nix: Metall. Trans. A, 17A (1986), 281.

15) G. S. Ansell and J. Weertman: Trans. Am. Inst. Min., Metal. Pet. Eng., 215 (1959), 838.

16) K. Maruyama and H. Oikawa: Collected Abstracts of the 1988 Spring Meeting of the Japan Inst. Metals, Japan Inst. Met., Sendai, (1988), 124.

17) L. M. Brown and R. K. Ham: Dislocation-Particle Interactions, in Strengthening Methods in Crystals, ed. by A.
Kelley and R. B. Nicholson, (1971), 9.

18) G. Y. Ghin: The Role of Preferred Orientation in Plastic Deformation, in The Inhomogeneity of Plastic Deformation, ed. by R. E. Read-Hill, ASM, Metals Park, OH, (1973), 83.

19) H. J. Frost and M.F. Ashby: Deformation Mechanism Maps, Pergamon Press, New York, (1982).

(Originally published in Tetsu-to-Hagané, 76 (1990), 1171, in Japanese) 